\title{
Evolution and Development of the Mammalian Cerebral Cortex
}

\author{
Zoltán Molnár ${ }^{\mathrm{a}} \quad$ Jon H. Kaas ${ }^{\mathrm{b}} \quad$ Juan A. de Carlos ${ }^{\mathrm{e}}$ Robert F. Hevner ${ }^{\mathrm{d}} \quad$ Ed Lein ${ }^{\mathrm{c}}$ \\ Pavel Němec ${ }^{f}$ \\ ${ }^{a}$ Department of Physiology, Anatomy and Genetics, University of Oxford, Oxford, UK; ${ }^{b}$ Vanderbilt University, \\ Nashville, Tenn., and 'Allen Institute for Brain Science, and d Seattle Children's Research Institute Center for

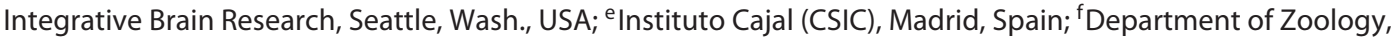 \\ Faculty of Science, Charles University in Prague, Prague, Czech Republic
}

\section{Key Words}

Comparative transcriptomics - Cortical arealization - Cortical neurogenesis · Intermediate progenitors · Subterranean vision - Tangential neuronal migration

\begin{abstract}
Comparative developmental studies of the mammalian brain can identify key changes that can generate the diverse structures and functions of the brain. We have studied how the neocortex of early mammals became organized into functionally distinct areas, and how the current level of cortical cellular and laminar specialization arose from the simpler premammalian cortex. We demonstrate the neocortical organization in early mammals, which helps to elucidate how the large, complex human brain evolved from a long line of ancestors. The radial and tangential enlargement of the cortex was driven by changes in the patterns of cortical neurogenesis, including alterations in the proportions of distinct progenitor types. Some cortical cell populations travel to the cortex through tangential migration whereas others migrate radially. A number of recent studies have begun to characterize the chick, mouse and human and nonhuman primate cortical transcriptome to help us understand how gene expression relates to the development and anatomical and functional organization of the adult neocortex. Although all
\end{abstract}

mammalian forms share the basic layout of cortical areas, the areal proportions and distributions are driven by distinct evolutionary pressures acting on sensory and motor experiences during the individual ontogenies.

(C) 2014 S. Karger AG, Basel

\section{Abbreviations used in this paper}

$\mathrm{CP} \quad$ cortical plate

C-R Cajal-Retzius

DII delta-like

E embryonic day

IFL inner fibre layer

IP intermediate progenitor

IPC intermediate progenitor cell

ISVZ inner subventricular zone

IZ intermediate zone

OSVZ outer subventricular zone

RG radial glia

SP subplate

SVZ subventricular zone

V1 primary visual cortex

$\mathrm{VZ} \quad$ ventricular zone

\section{KARGER}

E-Mail karger@karger.com

www.karger.com/bbe (c) 2014 S. Karger AG, Basel

0006-8977/14/0832-0126\$39.50/0
Zoltán Molnár, MD, DPhil, Professor of Developmental Neuroscience Department of Physiology, Anatomy and Genetics, University of Oxford Le Gros Clark Building, South Parks Road Oxford OX1 3QX (UK)

E-Mail zoltan.molnar@ dpag.ox.ac.uk 


\section{Introduction}

Elucidation of the evolvement of the mammalian isocortex (neocortex) to its present complex state is a fascinating topic for neuroscience, genetics, bioinformatics and comparative biology. It is a fundamental task to identify the developmental processes that evolved to generate a sixlayered neocortex rather than an earlier cortex resembling the dorsal cortex of reptiles, with a single layer of pyramidal cells, a scattering of intrinsic inhibitory neurons and only a few functional divisions. To gain more insight into these developmental patterns, we have studied the development and adult organization of various extant mammalian species to correlate cortical cell numbers and neuronal cell types with the cortical progenitor populations, with the elaboration of radial and tangential developmental migratory paths and with their modes of proliferation in different species. We consider the issues under 5 headings.

(1) The organization of the neocortex in functionally distinct areas and its level of cellular and laminar specialization will be reviewed in early mammals. The cortical specializations that occurred as early mammals diverged and modern mammals emerged will be considered.

(2) Several sectors of the telencephalic germinal zones contribute to the cells of the cerebral cortex and many of these cells arrive via tangential migratory pathways. Conserved and changing patterns of early tangential migration to the telencephalon will be reviewed with a focus on the cells migrating into the olfactory bulb and cerebral cortex.

(3) Various progenitors contribute to the formation of cortical layers and cell types through specific lineages. These include ventricular or apical radial glia (RG), subventricular (or basal) intermediate progenitors (IPs) and subventricular (outer) RG cell types. The key questions here relate to the regulation of brain size and folding.

(4) An increasing knowledge of neuronal numbers, cell types and their molecular taxonomy is currently redefining our view of cortical anatomy. The characterization of chick, mouse, and human and nonhuman primate cortical transcriptomes shows how gene expression relates to the development and functional organization of the neocortex.

(5) Comparative studies on species with limited visual input provide valuable models to study the contribution of sensory inputs to cortical specialization. Understanding the evolutionary effects of sensory deprivation on cortical development is fundamental for revealing genetic and environmental factors that allocate cortical territories for the various sensory and motor representations during normal development and in pathological conditions.

The Mammalian Cerebral Cortex
Reconstructing the Evolution of the Neocortex from the First Mammals to Humans

Mammals represent the only surviving branch of the synapsid clade radiation of stem amniotes that also gave rise to the sauropsid clade with surviving reptiles and birds. All surviving mammals are believed to have evolved from a single common ancestor that produced six major branches of mammalian evolution [Murphy et al., 2004] and an estimated 56,000 different species. All mammals that have been studied are characterized by a dorsal cap of the neocortex in the forebrain that differs from its homologue, the dorsal cortex, in reptiles by having six cortical layers and a number of structurally and functionally specialized subdivisions, the cortical areas. A major question is how this six-layered neocortex emerged from an earlier cortex that probably resembled the dorsal cortex of reptiles, with a single layer of pyramidal cells, a scattering of intrinsic inhibitory neurons and few functional divisions [Molnár, 2011].

The fossil record is never as complete and informative as we would hope, but enough evidence has accumulated from well-preserved skulls to indicate that most early mammals were small and had small brains with little neocortex (fig. 1). The olfactory piriform cortex and olfactory bulbs were relatively large (dominating the surface of the forebrain), which clearly indicated that the processing of olfactory information was paramount and that the neocortex had a limited role in guiding behavior. It is difficult to deduce how this small, thin cap of the neocortex was organized, but powerful inferences can be made from the results of the many studies on the cortical organization in the brains of currently living species. Studies on the cortical organization and structure have been most informative when conducted on small-brained mammals with little neocortex across the six major branches of the mammalian radiation, because this cortex has fewer subdivisions, and shared features are not as likely to be hidden in a maze of more recently derived cortical areas. Features such as cortical areas shared across members of all six major branches of the mammalian radiation are those most likely to be retained from a common ancestor (fig. 1).

Early primates were characterized by an increase in the number of visual areas, and an expansion of occipital and temporal visual cortices, as well as an expansion of posterior parietal sensorimotor areas that further connected visual and somatosensory cortices to motor and premotor cortices. Overall, the neocortex was enlarged, and neuronal packing density in the cortex was increased, especially in the primary visual cortex [Herculano-Houzel 


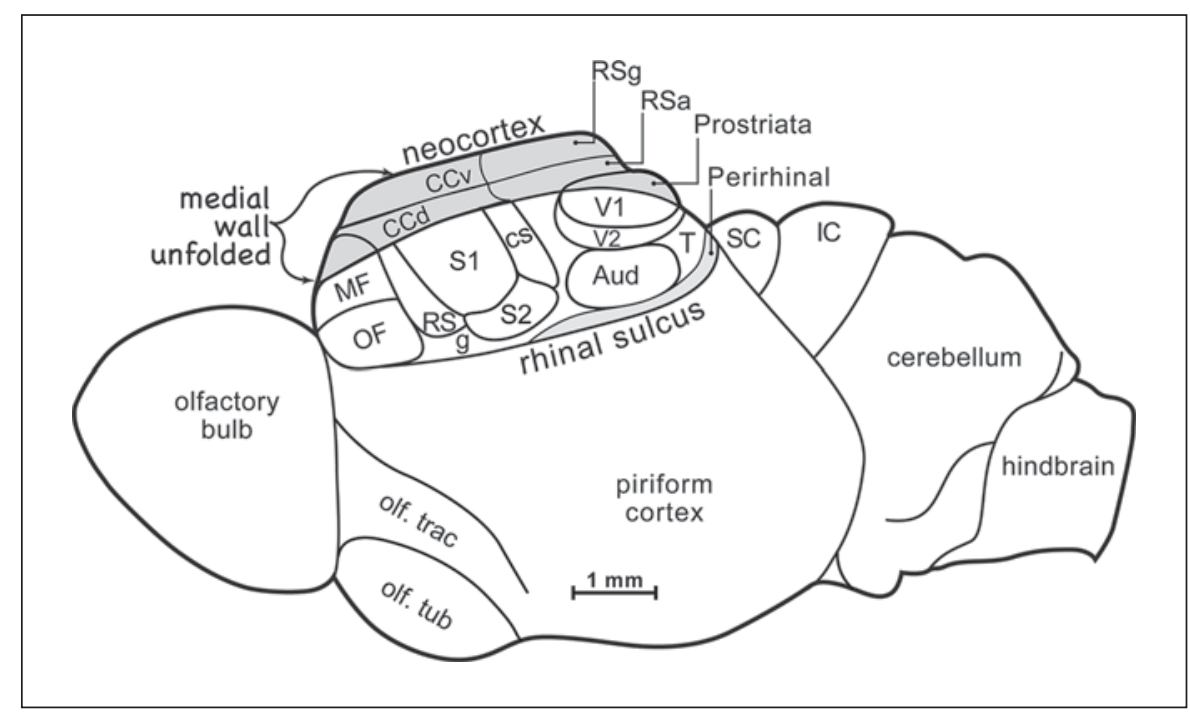

Fig. 1. The proposed organization of neocortex in early mammals. The proportion of the forebrain devoted to the neocortex of early mammals was small compared to that in most subsequent mammals, and there were few cortical areas. Neocortex included orbital frontal (OF) and medial frontal (MF) areas, primary somatosensory cortex (S1) bordered by secondary (S2), dorsal (RS) and caudal somatosensory areas (CS), possibly a gustatory area (g), and primary (V1), secondary (V2) and temporal visual areas (T), auditory cortex of one or more divisions (Aud), ventral (CCv) and dorsal cingulate areas (CCd), and retrosplenial granular (RSg) and agranular areas (RSa) as well as an area prostriata, a visual area. The superior (SC) and inferior colliculus (IC) of the midbrain were not covered by neocortex or cerebellum, and the olfactory bulb and piriform cortex were proportionately large. et al., 2007; Collins et al., 2010], and structural differences between some of the cortical areas became more pronounced [Wong et al., 2010]. The smallest of extant anthropoid primates, the marmosets, have brains in the range of 300-400 g that contain well under 1 billion neurons, while the massive human brain of $1,500 \mathrm{~g}$ has over 85 billion neurons [Herculano-Houzel et al., 2007; Azevedo et al., 2009]. Much more needs to be known about how brains and functional parts of brains vary in neuron numbers.

The neocortex of some anthropoid primates became extremely large, especially in humans where the neocortex comprises $80 \%$ of the massive brain. The extensive sheet of the neocortex is divided into an estimated 200 areas in each human hemisphere, and some regions and areas are specialized in different ways in each hemisphere, adding to the complexity to the cortex and behavioral capabilities [Kaas, 2013].

\section{Dynamics of the Movements of Cell Populations}

during Telencephalic Development in Mammals

The cortical neuroepithelium is a pseudostratified columnar epithelium containing densely packed cells. The germinative area is at the ventricular surface of the telencephalon. Neurons are generated here in the ventricular zone in successive waves during the developmental period. Generated cells move away from their site of neurogenesis to reach a specific destination closer to the pial surface of the same or of a different cortical area. Two distinct mechanisms allow newborn neurons to reach their final destinations: radial or tangential migration. In radial migration, the nuclei of cortical newborn cells move from their place of origin in the ventricular zone toward the pial surface, following an inside-out sequence [Angevine and Sidman, 1961]. They can stop at different levels of their trail to colonize different strata, in accord with their birth dates, and thus initiate the layered structure of the cerebral cortex. It was Rakic [1972] who revealed that newborn cells attach to the RG and use them as a scaffold to migrate to the final cortical laminar destination. The neurogenetic nature of RG cells was directly demonstrated [Noctor et al., 2001; Tamamaki et al., 2001]. However, it has now been shown that not all daughter cells remain near to the overlying cerebral area where they are generated [Walsh and Cepko, 1993]. In fact, there is a nongliophilic tangential migratory mechanism that allows cells to move for long distances and colonize other brain regions, which are sometimes very far away from their site of origin (fig. 2). 
Tangential Migratory Mechanisms Contribute to

Olfactory and Cerebral Cortical Development

De Carlos et al. [1996] have described that some cells generated in the subpallial ganglionic eminences migrate toward the cortical neuroepithelium, cross the corticostriate boundary and move long distances coursing tangentially into the preplate/marginal zone of the neocortical primordium. Subsequently, this finding was confirmed and extended by new data showing that these tangentially migrating cells were GABAergic [Anderson et al., 1997; Tamamaki et al., 1997].

The olfactory cortex is the first region to differentiate into the telencephalon in mice [from embryonic day (E) 11]. It occupies the ventrolateral part of the telencephalon and includes several structures: the piriform cortex, olfactory tubercle and entorhinal cortex (fig. 2a, b). The olfactory cortex is formed as a consequence of the convergence of numerous cell populations each of which is generated in different areas of the telencephalon [García-Moreno et al., 2007, 2008; Ceci et al., 2012; Pedraza and De Carlos, 2012].

The neocortex is the largest structure formed in the telencephalon by the same convergence of diverse cell populations each of which is generated in different proliferative areas throughout the telencephalon. These populations are: Cajal-Retzius (C-R) cells, subplate (SP) cells, interneurons and projection neurons. C-R cells are mainly generated between E10.5 and E11.5 in the mouse. They are generated in an extracortical structure that is situated in the medial and caudal part of the telencephalon, called the cortical hem. The cells then migrate tangentially, subpially and obliquely through the cortical preplate from caudal/medial to rostral/lateral areas to cover the entire cerebral cortex within 24 h [García-Moreno et al., 2007; Ceci et al., 2010; Miquelajáuregui et al., 2010].

SP cells are generated concurrently with C-R cells and, in the beginning, occupy the same cortical strata: the preplate. It is considered that this cell type is generated in the cortical ventricular zone, but it has been recently described that an important part of this heterogeneous population is generated in an extracortical area in the rostromedial telencephalic wall and reach the cortex by tangential migration [Pedraza and De Carlos, 2012; Pedraza et al., 2014] (fig. 2b, c). The first cells to send axons out of the cortical neuroepithelium are a subpopulation of SP cells [Marín-Padilla, 1971; McConnell et al., 1989; De Carlos and O'Leary, 1992]; however, the main and most important projecting cells of the cortex are the large, medium and small pyramidal cells. It is accepted that these cells are generated in the germinative area (VZ/SVZ) of

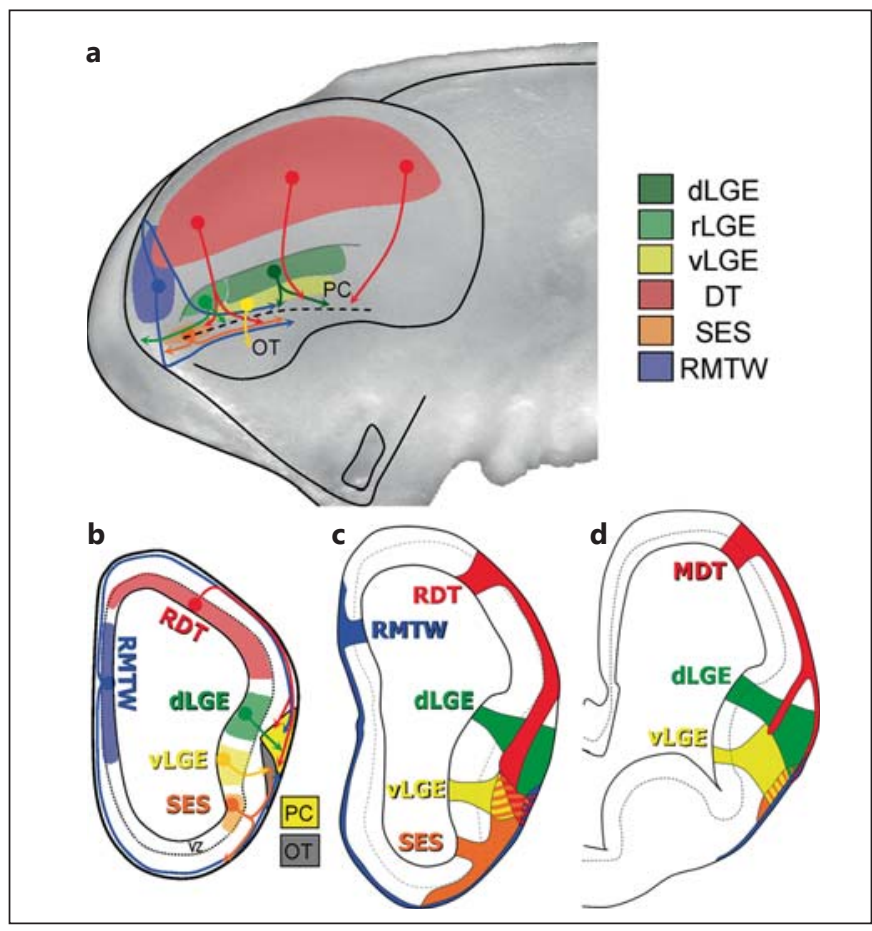

Fig. 2. The sites of generation of cortical nerve cells as well as their migratory routes are summarized here for tangentially migrating cell populations that contribute to the development of various telencephalic structures. a Lateral view of the left hemisphere. b-d Coronal sections from anterior, middle and posterior levels of a E11 mouse brain. The olfactory cortex is the first structure developed in the telencephalon (from E11 in mouse). This occupies the ventrolateral part of the hemisphere and consists of several structures: the piriform cortex (PC), olfactory tubercle (OT) and entorhinal cortex (EC). Each of these areas is formed by the migration of several cell populations generated in different telencephalic sites [García-Mereno et al., 2008]. The vast majority of cells that project from the cortex (pyramidal neurons) is generated in the germinative area of the cortical neuroepithelium of the dorsal telencephalon (DT), and the cortical interneurons are generated in the basal telencephalon, specifically in the three subdivisions of the ganglionic eminences (lateral, medial and caudal; $\mathrm{dLGE}=$ dorsolateral ganglionic eminence; vLGE = ventral lateral ganglionic eminence; rLGE = rostral portion of the lateral ganglionic eminence). SES indicates the region of the septo-eminential sulcus, RDT indicates the rostral part of the dorsal telencephalon and MDT the medial part. The development of the cerebral cortex starts in the following sequence: Cajal-Retzius cells are mainly generated between E10.5 and E11.5 in a caudomedial extracortical structure called the cortical hem and they migrate tangentially, subpially and obliquely (from caudal/medial to rostral/lateral areas). Subplate cells are cogenerated at the same time as Cajal-Retzius cells and, in the beginning, they occupy the same cortical stratum in the preplate. Recent work showed that a considerable proportion of subplate neurons originates from the rostral and medial telencephalic wall (RMTW) [Pedraza et al., 2014]. 
the neocortical neuroepithelium and migrate along the RG to settle in their particular laminae, contributing to cortex layering. Cortical interneurons are generated in the subpallial ganglionic eminences, specifically in each of the three subdivisions of the ganglionic eminence (lateral, medial and caudal; see fig. 2 for a summary) and enter the neuroepithelium by tangential migration [De Carlos et al., 1996; Anderson et al., 1997; Tamamaki et al., 1997].

Comparative developmental studies of avian and reptilian brains have shown that dorsal telencephalic structures are formed by several cell populations that are generated in distinct areas [Cobos et al., 2001; Tuorto et al., 2003; Métin et al., 2007]. The extent to which this process is contributing to human cortical development is currently a subject of debate [Clowry et al., 2010; Hansen et al., 2011; Molnár and Butt, 2013].

Recent comparisons of the proportions of several cortical progenitors in selected species during embryonic neurogenesis have revealed the elaboration and cytoarchitectonic compartmentalization of the germinal zone, with alterations in the proportions of various progenitor types [Martinez-Cerdeño et al., 2006; Cheung et al., 2010; Hevner and Haydar, 2012].

\section{Molecular and Cellular Characteristics of Cerebral Cortical IPs}

Progenitor cells that divide at a distance from the ventricular surface were recognized in many classic studies [reviewed by Hevner, 2006], but the significance of nonsurface mitoses remained uncertain until 2004. A trio of time-lapse imaging studies [Haubensak et al., 2004; Miyata et al., 2004; Noctor et al., 2004] showed that the basal or abventricular ('nonventricular surface' or 'nonapical') divisions in the embryonic rodent neocortex are neurogenic (not gliogenic) and produce glutamatergic (but not GABAergic) neurons. Those studies also showed that IPs are derived from RG progenitors, proliferate for only one or two mitotic cycles before differentiating into postmitotic neuroblasts, and extend and retract processes suggesting possible stages of IP migration. Since then, our views of the role of IPs in cortical neurogenesis have evolved. Here we focus on: (1) molecular profiles of IPs; (2) apical and basal types of IPs; (3) Delta-Notch signaling by IPs, and (4) IP contributions to cortical layers.

\section{Molecular Profiles of IPs}

While IPs were first distinguished by their cellular properties, molecular analyses have yielded many key insights. IPs express unique transcriptomic profiles, includ- ing the expression of transcription factor Tbr2 (also known as Eomes) in all cortical IPs [Englund et al., 2005; Kawaguchi et al., 2008; Ayoub et al., 2011; Cameron et al., 2012]. Dozens of IP-enriched genes have been identified: examples include Neurog2, Hes6 and Rasgef1b [Kawaguchi et al., 2008; Ayoub et al., 2011]. Nevertheless, IPs are far from homogeneous. Molecular profiling distinguished two types of IPs [Kawaguchi et al., 2008], and revealed temporal and spatial diversity as different cortical layers and areas are generated [Elsen et al., 2013]. Expression of genes such as Svet 1 and Cux2 suggested that IPs contribute to upper cortical layers [Tarabykin et al., 2001; Zimmer et al., 2004], although not exclusively. Expression of Scrt2 suggested that IPs move from VZ to SVZ by a type of epithelial-mesenchymal transition [Itoh et al., 2013]. Molecular analyses implicated IPs in Delta-Notch signaling [Kawaguchi et al., 2008; Nelson et al., 2013]. Molecular comparisons are also telling us about the evolution of IPs [Lui et al., 2011; Molnár and Clowry, 2012].

\section{Apical and Basal IP Types}

Unbiased microarray profiling of $>100$ single cells isolated from the VZ and SVZ of E14.5 mice distinguished four types of cells: RG, new postmitotic neurons and two types of IPs. The latter, now known as apical and basal IPs [Hevner and Haydar, 2012], segregated into the VZ and SVZ, respectively [Kawaguchi et al., 2008]. Apical IPs exhibit short radial bipolar morphology and sometimes contact the ventricular surface, while basal IPs usually exhibit multipolar morphology [Kowalczyk et al., 2009]. Short radial progenitors were independently found by another approach using reporter plasmids electroporated into VZ cells [Gal et al., 2006]. Interestingly, the so-called 'short neural precursors' showed electron-microscopic evidence of apical (ventricular) surface contact. More recent work has confirmed that short neural precursors express Tbr2 [Tyler and Haydar, 2013]. The classification of IPs into apical and basal types (fig. 3a) is therefore supported by molecular and morphological correlations [Hevner and Haydar, 2012].

\section{Delta-Notch Signaling by IPs}

Canonical Notch receptor signaling is essential to maintain RG progenitor identity and to thereby prevent the premature onset and cessation of cortical neurogenesis [Imayoshi et al., 2010]. IPs play an essential role in this process [Yoon et al., 2008]. Specifically, IPs highly express Notch receptor ligands delta-like (Dll) 1 on both apical and basal IPs, and Dll3 on basal IPs only [Kawaguchi et al., 2008; Nelson et al., 2013]. Interestingly, Dll1 


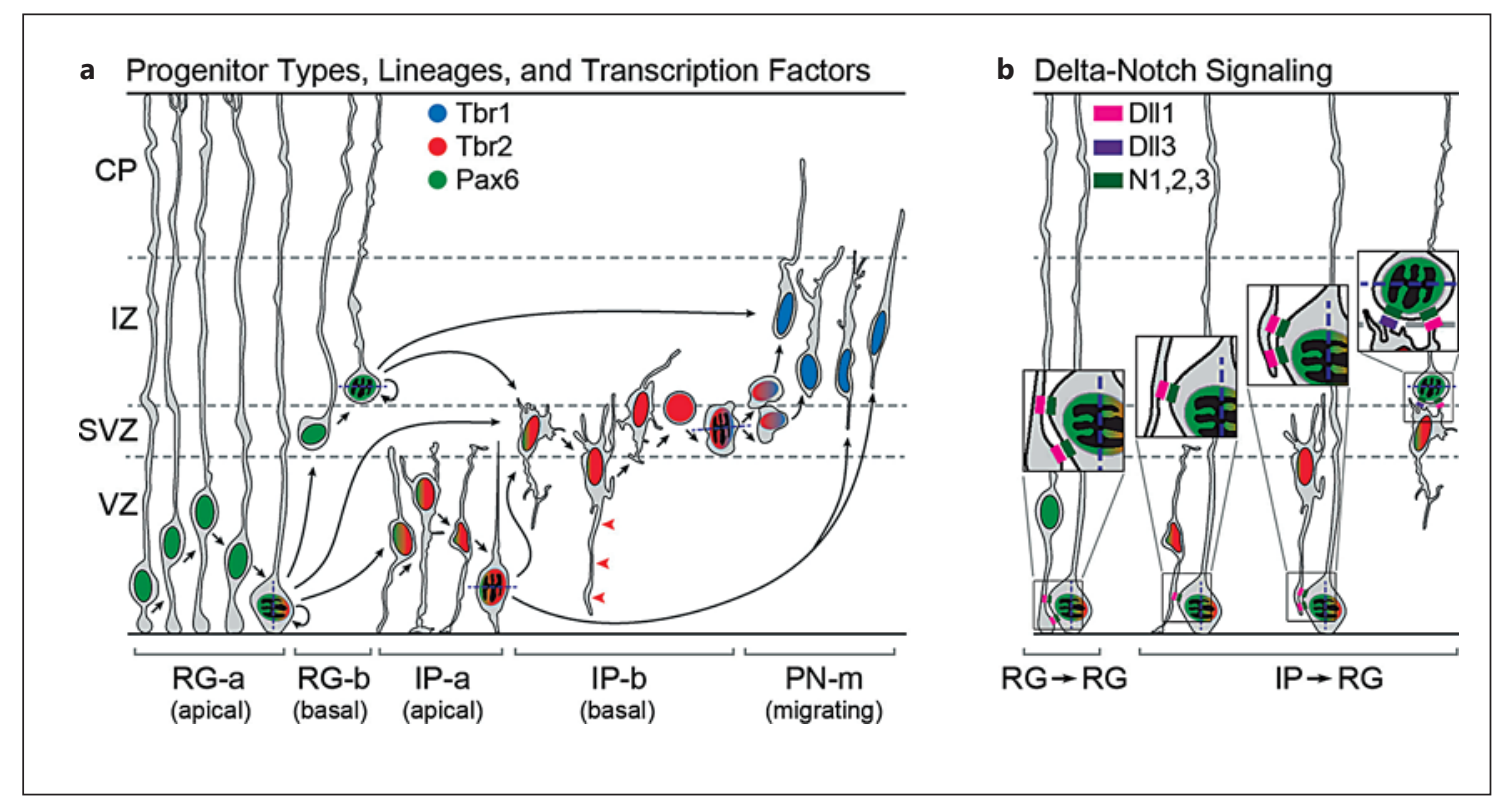

Fig. 3. Molecular and cellular characteristics of IPs. a IPs are produced from apical (RG-a) and basal RG (RG-b). IPs in the VZ exhibit short radial morphology and are attached to the ventricular/ apical surface (IP-a), while IPs in the SVZ exhibit multipolar morphology with no apical attachment (IP-b). The IP-b cells extend highly dynamic processes, some of which approach the ventricular/apical surface (red arrowheads). IPs divide to produce migrating projection neurons ( $\mathrm{PN}-\mathrm{m})$, which may also be derived directly from RG divisions. Differentiation from RG $\rightarrow \mathrm{IP} \rightarrow \mathrm{PN}-\mathrm{m}$ is associated with the sequential expression of transcription factors Pax6 $\rightarrow$ Tbr2 $\rightarrow$ Tbr1 [reviewed by Hevner et al., 2006]. b DeltaNotch signaling may occur from RG $\rightarrow$ RG and from IP $\rightarrow$ RG. Dll1 is expressed by RG progenitors and IPs, while Dll3 is expressed only by IP-b cells. Dll1 on IPs is localized to processes as well as cell bodies, while Dll3 on IP-b cells is limited to the cell body. Dll1 expression on IP-b cell processes may mediate longrange Delta-Notch signaling (middle IP $\rightarrow$ RG interaction). Insets show enlarged views of contacts indicated by boxes. protein is highly expressed on IP processes, including long apical processes that extend from the SVZ to the VZ where they contact mitotic RG at the apical surface [Nelson et al., 2013]. As demonstrated by time-lapse imaging, IP processes undergo rapid extension and retraction, suggesting involvement in cell migration [Tabata and Nakajima, 2003; Noctor et al., 2004] or, as the more recent evidence suggests [Nelson et al., 2013], Dll1-Notch signaling (fig. 3b).

\section{IP Contributions to Cortical Layers}

The hypothesis that IPs contribute predominantly to upper cortical layers (i.e. layers 2-4) was initially suggested by correlations between gene expression in the SVZ, where IPs are located, and in the upper (but not the lower) cortical layers. In particular, the expression patterns of Svet 1 (subsequently identified as an Unc5d intron [Sasaki et al., 2008]) and Cux2 supported this hypothesis [Tarabykin et al., 2001; Zimmer et al., 2004]. This hypothesis seemed to be in accord with coordinate evolutionary expansion of the SVZ and upper cortical layers [Krieg- stein et al., 2006]. However, other observations suggested that IPs produce the majority of glutamatergic neurons in all cortical layers [Haubensak et al., 2004; Pontious et al., 2008; Kowalczyk et al., 2009]. The contributions of IPs to cortical layers will ultimately have to be resolved by longterm lineage tracing of IPs to determine the laminar fates of daughter neurons. Preliminary studies using inducible conditional genetic lineage tracing in Eomes ${ }^{\mathrm{CrER}}$ mice [Pimeisl et al., 2013] suggest that IPs indeed contribute to all cortical layers, including SP and C-R neurons [Hevner, data not shown]. Similar observations have been made using the Tbr2:cre line [Vasistha et al., 2013]. In future studies, it will be interesting to determine if early IPs diversify into lineages committed to upper and lower cortical layer identities, as described for early RG progenitors [Franco et al., 2012].

IP Contributions to Cortical Expansion and Folding during Cortical Evolution

Evolutionarily, IPs are thought to be instrumental in the expansion of neocortical thickness and surface area by 

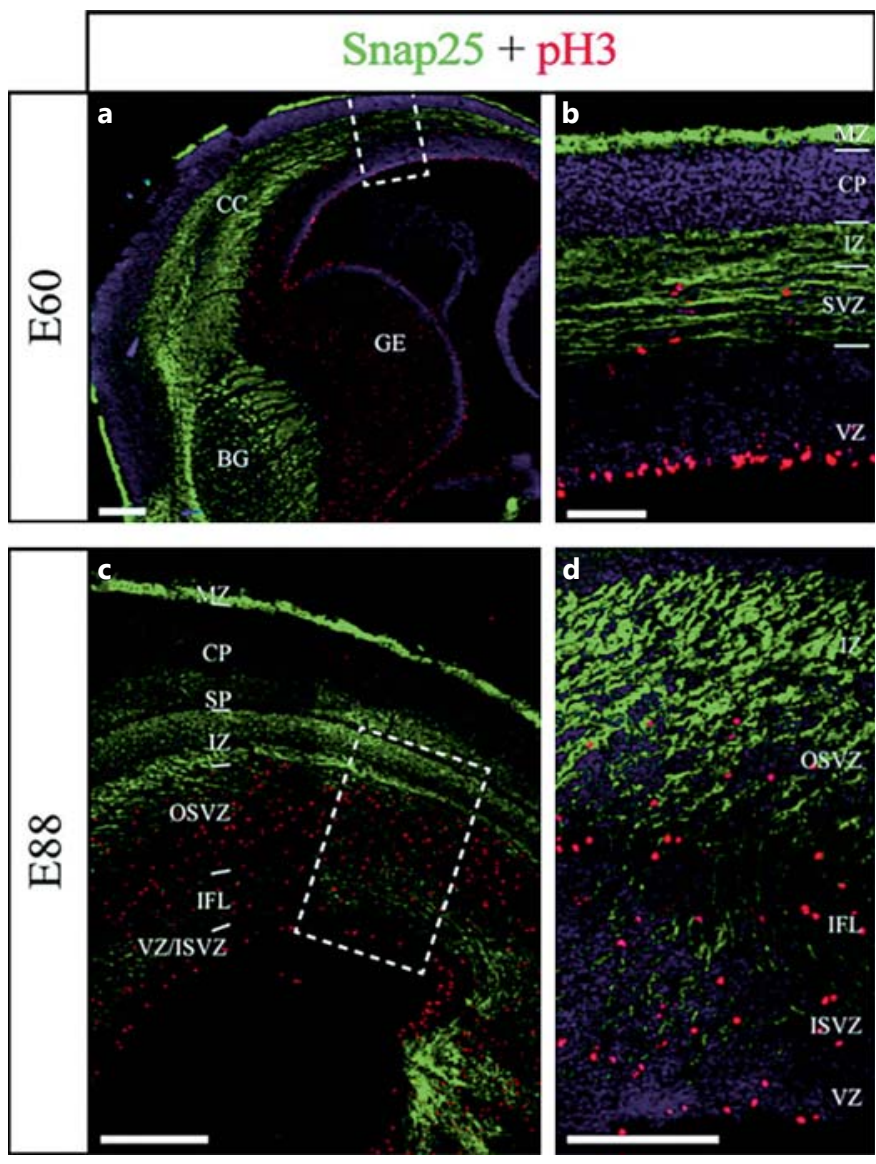

Fig. 4. Cytoarchitecture of the embryonic marmoset neocortical germinal zone is similar to that of developing primate brains that have convolutions (sulci and gyri). Snap25 immunoreactivity showed an extensive fiber layer at $\operatorname{E60}(\mathbf{a}, \mathbf{b})$ and E88 (c, d). a At E60, Snap25 (green) immunoreactivity revealed a broad band of fiber fascicles crossing below the ganglionic eminence (GE) close to the anlage of the basal ganglia (BG) on coronal sections. b The SVZ contained $\mathrm{pH} 3+$ nuclei (red). The VZ and CP showed relatively less fiber labeling at this stage. c At E88, the Snap25+ fibers showed variations in their density and orientation in different layers. SP, IZ, upper part of the outer SVZ (OSVZ) and internal fiber layer (IFL) contained fibers with parallel trajectories to the pial and ventricular surfaces. The fibers were perpendicular to the ventricular surface with the lower part of the OSVZ. The VZ contained relatively few labeled fibers. Scale bars $=200 \mu \mathrm{m}$ [figure from García-Moreno et al., 2012.]

amplifying the output from the cortical germinal zone [Martinez-Cerdeño et al., 2006; Cheung et al., 2010]. In developing macaque and human cortices, Smart et al. [2002] identified cytoarchitectonically distinct subdivisions within the SVZ, designated the inner and outer SVZ, separated from each other by an inner fiber layer. García-Moreno et al. [2012] examined a gyrencephalic rodent, the agouti (Dasyprocta agouti), and a lissencephalic primate, the marmoset monkey (Callithrix jacchus), and identified very similar cytoarchitectonic distinction between the outer and inner SVZ at midgestation in both species. Regardless of the brain folding, the proportions of RG, IPs and outer RG cell populations were similar in the lissencephalic marmosets at midgestation as in gyrencephalic humans or ferrets [García-Moreno et al., 2012]. Kelava et al. [2012] conducted a similar study in the marmoset at midgestation. Their observations suggest that cytoarchitectonic subdivisions of the SVZ are an evolutionary trend and not a primate-specific feature, and that a greater population of outer RG can be seen in larger brains regardless of phylogeny or cortical folding (fig. 4). Hevner and Haydar [2012] proposed that differential regulation of basal RG and other progenitor types might enhance the adaptability and diversity of cortical morphogenesis. Recent studies in transgenic mice support this idea and confirm that IPs are critical in the genesis of cortical gyri and sulci [Nonaka-Kinoshita et al., 2013; Rash et al., 2013; Stahl et al., 2013].

\section{Transcriptional Landscape of the Developing Human Cortex}

Development of the cellular and functional architecture of the neocortex is to a large extent the product of tightly regulated gene transcriptions, and the unique features of human cortical function are presumably largely a function of differences in transcriptional regulation between species. A number of recent studies aimed to characterize the mouse, human and nonhuman primate cortical transcriptome to elucidate how gene expression relates to the development and functional organization of the neocortex [Abrahams et al., 2007; Johnson et al., 2009; Belgard et al., 2011; Colantuoni et al., 2011; Kang et al., 2011; Bernard et al., 2012; Hawrylycz et al., 2012]. To understand these transcriptional programs and allow comparative analyses to identify similarities and differences between human and other species, over the last decade the Allen Institute for Brain Science has created a series of transcriptional atlases of the developing and adult human [Hawrylycz et al., 2012], nonhuman primate and mouse brains [Lein et al., 2007] as freely accessible data resources for the scientific community (available at www. brain-map.org). In the neocortex, these atlases analyze the transcriptome at different levels of anatomical resolution and breadth spanning the laminar and areal extent of the cortex as well as at different stages of cortical development. The Allen Human Brain Atlas uses DNA microarrays for transcriptional profiling of several hundred lo- 
Fig. 5. Restricted expression of neurogenic genes PAX6 and TBR2 in the proliferative layers of the 15 postconceptual week ( $\mathrm{pcw}$ ) midgestational human brain on coronal sections. Normalized expression levels (red high, green low) from microarray analysis of individually isolated brain regions are plotted on anatomical parcellations of an age-matched digital reference atlas (www. brainspan.org).

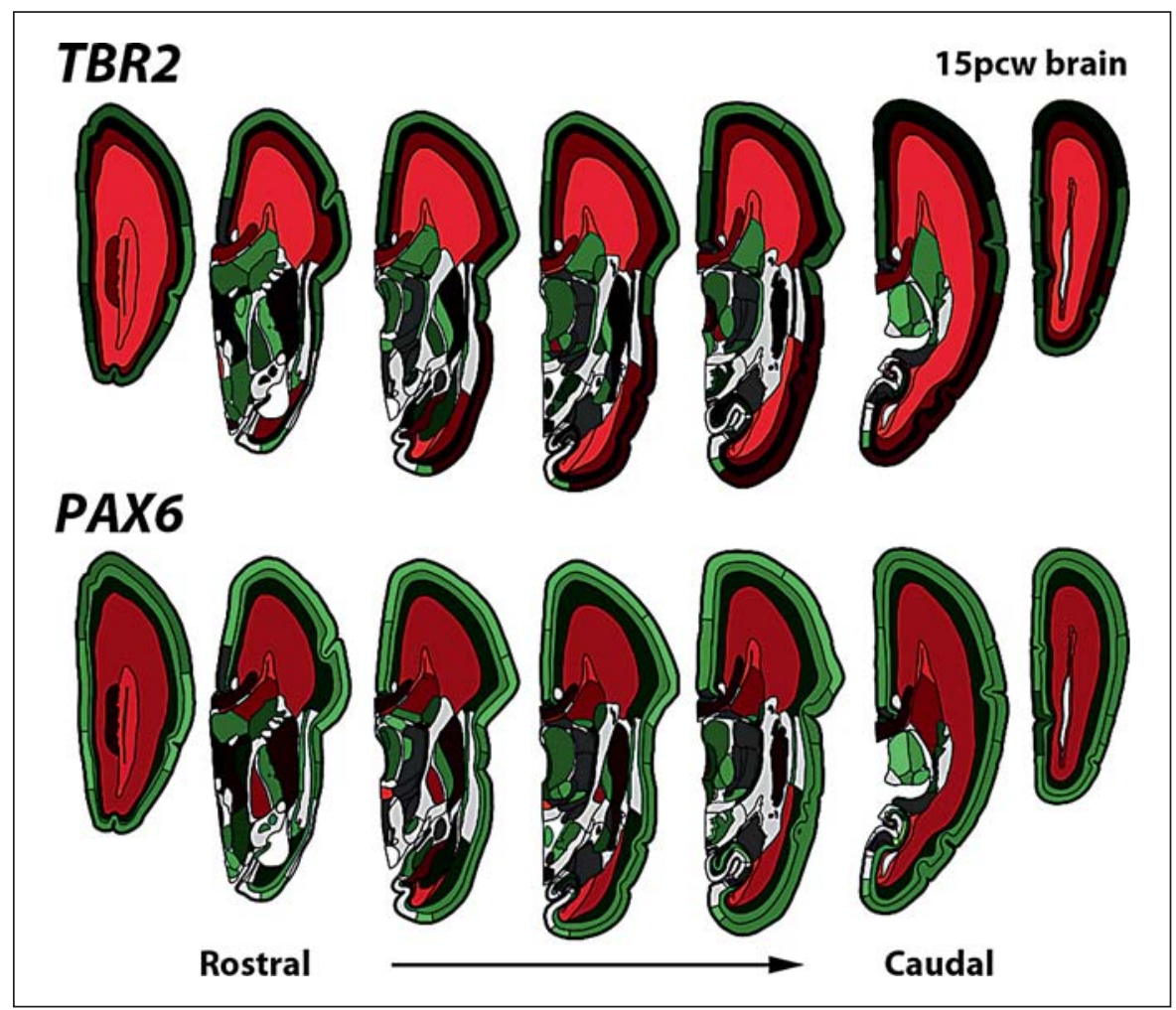

cations spanning the adult human neocortex [Hawrylycz et al., 2012], while NIH Blueprint Non-Human Primate Atlas profiles individual cortical layers in the rhesus monkey. Similarly, the BrainSpan Atlas of the Developing Human Brain is a resource for studying the transcriptome across human brain development, using RNA-Seq on discrete cortical regions across the entire life span, as well as with microarrays at higher resolution in the midgestational cortex on laser-microdissected individual layers of different regions of the developing neocortex. These latter data allow the analysis of the detailed anatomical distribution of transcripts in the prenatal human cortex, such as the expected enrichment of the neurogenic genes PAX6 and TBR2 in RG and IPs of the ventricular and subventricular zones (fig. 5). The availability of these data provides a rich resource for understanding neocortical development and identifying features that are distinct in human brain development.

Several broad themes about the transcriptional architecture of the neocortex emerge from analyses of these data. In the mature cortex, the greatest transcriptional variation is seen across cortical layers and major cell classes, representing differential expression across the different neuronal and nonneuronal cells making up the cortex
[Belgard et al., 2011, 2013; Molnár and Belgard, 2012]. Relatively smaller variation is seen across cortical areas in the adult, reflecting the common stereotyped architecture of the neocortex as a whole, although there is a strong relationship between physical proximity and transcriptional similarity [Hawrylycz et al., 2012]. These graded relationships across the cortex are reminiscent of early gradient expression of cortical transcription factors responsible for areal specification [O'Leary et al., 2007], suggesting that these early gradients leave a lasting imprint on the transcriptome as a whole.

Differences in cortical cytoarchitectural specializations between primates and rodents have molecular correlates. For example, the highly specialized primary visual cortex (V1) in human and nonhuman primates shows distinctive gene expression patterns compared to other cortical regions [Bernard et al., 2012]. This unique regional patterning in V1 is not recapitulated in the rodent visual cortex. Looking more broadly in a comparative study of approximately 1,000 genes in human and mouse cortex, nearly one third showed differences between species [Zeng et al., 2012]. 
Role of Environmental Influences on the

Regionalization of the Mammalian Cerebral Cortex

The basic patterns of cortical areas are preprogrammed and develop from early cortical gradients; however, differences also begin to arise by local interactions with afferent neurons. Thalamic axons, which later will mediate most sensory information from the environment, reach the cortex at a very early stage, before the majority of cortical neurons have even been born [Molnár et al., 2012]. Although the early cortical patterning is autonomous and established with or without the presence of external input, recent work points to the crucial role of the early-developing thalamocortical projections and their interactions with the developing cortical circuitry in establishing some aspects of the functional and structural organization of the cortex. Cortical areas and their thalamic input can be experimentally duplicated, thus increasing in number, by manipulating the expression of genes that control cortical patterning during development [Shimogori and Grove, 2005; Assimacopoulos et al., 2012].

Molnár et al. [2012] are interested in the signaling mechanisms that set the coordinates for the further establishment of cortical areas with their specific connections, including thalamic inputs. It is a fundamental task to understand what genetic and environmental interactions allocate cortical territories for the various sensory and motor representations during normal development and in pathological conditions [Grant et al., 2012]. The effect of sensory deprivation on cortical development has been an important model to study the interaction between the unfolding genetic cortical developmental program and the environmental influence [Rakic, 1988; Dehay and Kennedy, 2007; Reillo et al., 2011]. In this review, comparative studies on species with limited visual input shall be discussed in more detail. These species provide valuable models to study the contribution of sensory inputs to cortical specializations [Catania and Kaas, 1995; Catania and Remple, 2002; Němec et al., 2007].

Structure and Function of Subterranean Vision

Among mammals, approximately 300 species have adapted to the stable, low-oxygen and mainly lightless underground ecotope [Nevo, 1999]. Eye sizes and degree of the visual system reduction vary substantially across subterranean mammals [Němec et al., 2007]. Some strictly subterranean species, such as the blind mole rats of the genus Spalax, possess minute, subcutaneous eyes with degenerated optical apparatus and a vestigial visual system, the only function of which is to detect ambient light levels for photoperiodic perception [Nevo, 1999]. Although the primary visual cortex (V1) is present in Spalax ehrenbergi, cortical visual processing is severely impaired by lack of retinotopic organization within the geniculostriate pathway [Cooper et al. 1993]. Moreover, no visually evoked potentials could be recorded in the occipital cortex [Haim et al., 1983; Necker et al., 1992]. Instead, electrophysiological and 2-deoxyglucose mapping experiments revealed that occipital regions, which are occupied by the visual cortex in sighted mammals, can be activated by somatosensory [Necker et al., 1992] and auditory stimuli [Heil et al., 1991; Bronchti et al., 2002].

Strictly subterranean, congenitally microphthalmic African mole rats (Rodentia, Bathyergidae), by contrast, possess structurally normal eyes that have retained the capability of image-forming vision [Němec et al., 2008]. They exhibit unique photoreceptor properties [Peichl et al., 2004]. The rod-dominated retina of the African mole rats contains significant cone populations $(\sim 10 \%)$ expressing dominantly $S$ opsin, which seems to be sensitive to blue light in bathyergids [Kott et al., 2010]. Many of these $\mathrm{S}$ cones coexpress small amounts of $\mathrm{L}$ opsin (sensitivity to green or yellow). Only few pure L cones express exclusively the L opsin. Although behavioral experiments have confirmed that L cones subserve green/green-yellow light sensing at photopic levels [Kott et al., 2010], an extremely sparse population of L cones likely contributes little to image-forming vision.

The total number of optic nerve fibers ranges between 6,000 in Bathyergus suillus and 2,100 in Heliophobius argenteocinereus [Němec et al., 2008]. Visual acuity, estimated from counts of peak ganglion cell density and axial length of the eye, ranges between 0.3 and 0.5 cycles per degree [Němec et al., 2008]. The central visual system of bathyergids has undergone regression [Němec et al., 2004; Crish et al., 2006]. All the visual nuclei except for the suprachiasmatic nucleus receive almost exclusively contralateral retinal projections. The only well-developed visual domains are those involved in controlling the circadian and circannual biological rhythms - the suprachiasmatic nucleus and the retinohypothalamic projections. The lateral geniculate body is severely reduced in size, but still constitutes the major retinal target receiving about $60 \%$ of all retinal projections [Němec et al., 2008]. The pretectum is also only moderately reduced. By contrast, the superficial visual layers of the superior colliculus and the accessory optic system are vestigial [Němec et al., 2001, 2004]. This indicates that the bathyergid mole rats are poorly equipped for the detection and orientation towards objects in the visual field and for the tracking of moving objects. 


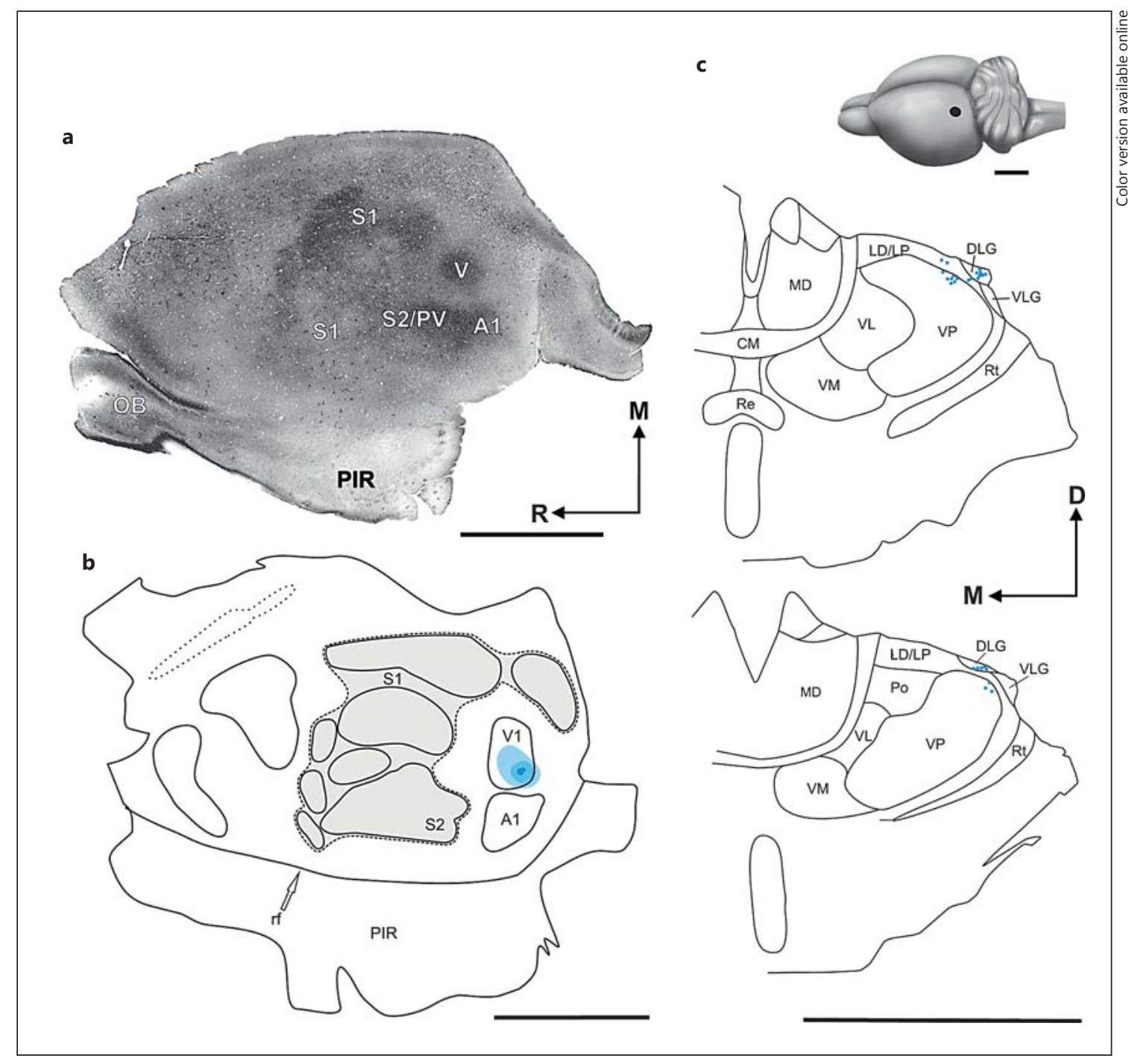

Fig. 6. Primary visual cortex (V1) in giant mole rat (Fukomys mechowii). a Section of flattened cortex stained for cytochrome oxidase (CO). CO-dense regions in the medial cortex and less obvious $\mathrm{CO}$-dense modules in the lateral cortex likely correspond to the primary somatosensory cortex (S1), regions in far caudolateral cortex likely correspond to the secondary somatosensory cortex (S2), parietal ventral area (PV), and primary visual (V1) and auditory cortex (A1). b, c Anatomical identification of V1. Injection of fluorescent tracer Fast Blue into a putative V1 resulted in retrograde labeling within the dorsal lateral geniculate nucleus (DLG) - clear evidence for the presence of a primary visual cortex. $\mathbf{b}$ Injection site. c Resulting distribution of retrogradely labeled neurons. Note that retrogradely labeled neurons were also distributed over the adjacent laterodorsal (LD) and/or lateral posterior thalamic nucleus (LP) and ventral posterior thalamic nucleus of the (VP). Upper right drawing of the F. mechowii brain shows the relative size and location of V1 (black oval). Its position is displaced laterally compared to other rodents. $\mathrm{CM}=$ Central medial thalamic nucleus; $\mathrm{D}=$ dorsal $; \mathrm{M}=$ medial $\mathrm{MD}=$ mediodorsal thalamic nucleus; $\mathrm{OB}=$ olfactory bulb; $\mathrm{PIR}=$ piriform cortex Po = posterior thalamic nuclear group; $\mathrm{R}=$ rostral; $\mathrm{Re}=$ nucleus reuniens of the midline thalamus; $\mathrm{rf}=$ rhinal fissure; $\mathrm{Rt}=$ reticular thalamic nucleus; $\mathrm{VL}=$ ventrolateral thalamic nucleus; VLG = ventral lateral geniculate nucleus; $\mathrm{VM}=$ ventromedial thalamic nucleus. Scale bars $=5 \mathrm{~mm}$.
The primary visual cortex (V1) is small and, in comparison to other rodents, displaced laterally (fig. 6). Such an unusual position appears to be a consequence of an expansion of the somatosensory cortex and might account for the failure of electrophysiological identification of V1 in Heterocephalus glaber [Catania and Remple, 2002; Henry et al., 2006]. Multiple injections of different tracers in different V1 regions resulted in retrograde labeling of a distinct region of the dorsolateral geniculate nucleus, implying conservation of the retinotopic organi- 
zation within the geniculostriate pathway [Miklušová et al., unpubl. data]. However, many injections into putative V1 resulted also in a robust retrograde labeling of the multimodal thalamic nuclei, namely the posterior thalamic and the lateral posterior thalamic nuclei (not shown). Indeed, retrograde projections to these structures were often much stronger than those to the dorsolateral geniculate nucleus. Thus, only part of the cytochrome oxidase-dense region in the far caudolateral cortex seems to correspond to V1, the rest of the area likely belongs to the associative cortex processing multimodal information. Another indication of the presence of a definable visual cortex comes from functional neuroanatomical mapping: stimulation by light after a period of dark adaptation elicits c-Fos expression in the occipital cortex of Fukomys anselli [Oelschläger et al., 2000]. Evolutionary reduction of the visual cortex in these strictly subterranean rodents seems to be coupled with expansion of the somatosensory cortex and with a robust multimodal thalamic input to the expected location of the primary visual cortex.

\section{Conclusion}

Comparative studies of the mammalian brain have revealed the level of cellular and laminar specialization that was present in the early mammalian cortex.

Comparative developmental studies indicate that the elaboration and cytoarchitectonic compartmentalization of the germinal zone combined with alterations in the proportions of various progenitor types correlate with the evolutionary enlargement of the mammalian cortex, but their relationship to brain folding is still not fully understood.

Tangential migration is employed in the delivery of various cell populations of the mammalian olfactory and cerebral cortex. This mechanism enabled the conver- gence of diverse glutamatergic and GABAergic neuronal populations to a specific cortical area where they organize themselves into complex neuronal circuits. Segregating neurogenesis in space and time produces cell diversity. Recent results suggest that some of the earliest generated cells of the cortex in the marginal zone and SP arrive through tangential migration to the cortex.

Transcriptome analysis of chick, mouse, human and nonhuman primate telencephalon help to understand how gene expression relates to the development and to the adult anatomical and functional organization of the neocortex. These expression data will have to be tested for causal relationships and combined with more quantitative anatomical data on cortical neuronal cell numbers, and proportions of cell types in particular areas and layers to reveal the evolutionary changes in circuit assembly.

While various mammals share the basic layout of cortical areas and largely rely on early cortical gradients for early differentiation, the particular areal proportions and distributions are driven by the sensory and motor experience during the individual's ontogenesis.

\section{Acknowledgments}

We are grateful to Prof. András Csillag and his team for organizing the 7th European Conference on Comparative Neurology in Budapest, Hungary. We thank Prof. Ray Guillery and Prof. Hans ten Donkelaar for editing our paper. Z.M. is supported by the Medical Research Council and BBSRC UK; J.H.K. is funded by NIH grant R01-NS16446. J.A.d.C.'s work was supported by a grant (BFU2010-21377) from the Spanish Ministry of Science and Innovation; R.F.H. is supported by NIH grants R21 MH087070 and RO1 MH080766-S. P.N.'s work was supported by the Czech Science Foundation (206/09/1364).

\section{Disclosure Statement}

The authors declare no conflict of interest.

\section{References}

Abrahams BS, Tentler D, Perederiy JV, Oldham MC, Coppola G, Geschwind DH (2007): Genome-wide analyses of human perisylvian cerebral cortical patterning. Proc Natl Acad Sci USA 104:17849-17854

-Anderson SA, Eisenstat DD, Shi L, Rubenstein JLR (1997): Interneuron migration from basal forebrain to neocortex: dependence on Dlx genes. Science 278:474-476.
Angevine JB, Sidman RL (1961): Autoradiographic study of cell migration during histogenesis of cerebral cortex in the mouse. $\mathrm{Na}$ ture 192:766-768.

-Assimacopoulos S, Kao T, Issa NP, Grove EA (2012): Fibroblast growth factor 8 organizes the neocortical area map and regulates sensory map topography. J Neurosci 32:71917201. youb AE, Oh S, Xie Y, Leng J, Cotney J, Dominguez MH, Noonan JP, Rakic P (2011): Transcriptional programs in transient embryonic zones of the cerebral cortex defined by highresolution mRNA sequencing. Proc Natl Acad Sci USA 108:14950-14955. 
Azevedo FAC, Carvalho LRB, Grinberg LT, Cobos I, Puelles L, Martínez S (2001): The avian Farfel JM, Ferretti REL, Leite REP, Filho WJ, Lent R, Herculano-Houzel S (2009): Equal numbers of neuronal and nonneuronal cells make the human brain an isometrically scaled-up primate brain. J Comp Neurol 513: 532-541.

- Belgard TG, Marques AC, Oliver PL, Abaan HO, Sirey TM, Hoerder-Suabedissen A, GarcíaMoreno F, Molnár Z, Margulies EH, Ponting CP (2011): A transcriptomic atlas of mouse neocortical layers. Neuron 71:605-616.

- Belgard TG, Montiel JF, Wang WZ, GarcíaMoreno F, Margulies EH, Ponting CP, Molnár Z (2013): Adult pallium transcriptomes surprise in not reflecting predicted homologies across diverse chicken and mouse pallial sectors. Proc Natl Acad Sci USA 110:1315013155.

Bernard A, Lubbers LS, Tanis KQ, Luo R, Podtelezhnikov AA, Finney EM, McWhorter MM, Serikawa K, Lemon T, Morgan R, Copeland C, Smith K, Cullen V, Davis-Turak J, Lee CK, Sunkin SM, Loboda AP, Levine DM, Stone DJ, Hawrylycz MJ, Roberts CJ, Jones AR, Geschwind DH, Lein ES (2012): Transcriptional architecture of the primate neocortex. Neuron 73:1083-1099.

Bronchti G, Heil P, Sadka R, Hess A, Scheich H, Wollberg Z (2002): Auditory activation of 'visual' cortical areas in the blind mole rat (Spalax ehrenbergi). Eur J Neurosci 16:311329.

Cameron DA, Middleton FA, Chenn A, Olson EC (2012): Hierarchical clustering of gene expression patterns in the Eomes+ lineage of excitatory neurons during early neocortical development. BMC Neurosci 13:90.

-Catania KC, Kaas JH (1995): Organization of the somatosensory cortex of the star-nosed mole. J Comp Neurol 351:549-567.

Catania KC, Remple MS (2002): Somatosensory cortex dominated by the representation of teeth in the naked mole-rat brain. Proc Natl Acad Sci USA 99:5692-5697.

-Ceci ML, López-Mascaraque L, de Carlos JA (2010): The influence of the environment on Cajal-Retzius cell migration. Cereb Cortex 20:2348-2360.

-Ceci ML, Pedraza M, de Carlos JA (2012): The embryonic septum and ventral pallium, new sources of olfactory cortex cells. PLoS One 7:e44716.

Cheung AF, Kondo S, Abdel-Mannan O, Chodroff RA, Sirey TM, Bluy LE, Webber N, DeProto J, Karlen SJ, Krubitzer L, Stolp HB, Saunders NR, Molnár Z (2010): The subventricular zone is the developmental milestone of a 6-layered neocortex: comparisons in metatherian and eutherian mammals. Cereb Cortex 20:1071-1081.

Clowry G, Molnár Z, Rakic P (2010): Renewed focus on the developing human neocortex. J Anat 217:276-288. telencephalic subpallium originates inhibitory neurons that invade tangentially the pallium (dorsal ventricular ridge and cortical areas). Dev Biol 239:30-45.

-Colantuoni C, Lipska BK, Ye T, Hyde TM, Tao R, Leek JT, Colantuoni EA, Elkahloun AG, Herman MM, Weinberger DR, Kleinman JE (2011): Temporal dynamics and genetic control of transcription in the human prefrontal

-Collins CD, Airey DC, Young NA, Leitch DB, Kaas JH (2010): Neuron densities vary across and within cortical areas in primates. Proc Natl Acad Sci USA 107:15927-15932.

Cooper HM, Herbin M, Nevo E (1993): Visual system of a naturally microphthalmic mammal: the blind mole rat, Spalax ehrenbergi. J Comp Neurol 328:313-350.

Crish SD, Dengler-Crish CM, Catania KC (2006): Central visual system of the naked mole-rat (Heterocephalus glaber). Anat Rec A Discov Mol Cell Evol Biol 288:205-212.

De Carlos JA, O’Leary DDM (1992): Growth and targeting of subplate axons and establishment of major cortical pathways. J Neurosci 12: 1194-1211.

- De Carlos JA, López-Mascaraque L, Valverde F (1996): Dynamics of cell migration from the lateral ganglionic eminence in the rat. J Neurosci 16:6146-6156.

Dehay C, Kennedy H (2007): Cell-cycle control and cortical development. Nat Rev Neurosci 8:438-450.

Elsen GE, Hodge RD, Bedogni F, Daza RA, Nelson BR, Shiba N, Reiner SL, Hevner RF (2013): The protomap is propagated to cortical plate neurons through an Eomes-dependent intermediate map. Proc Natl Acad Sci USA 110:4081-4086.

-Englund C, Fink A, Lau C, Pham D, Daza RA, Bulfone A, Kowalczyk T, Hevner RF (2005): Pax6, Tbr2, and Tbr1 are expressed sequentially by radial glia, intermediate progenitor cells, and postmitotic neurons in developing neocortex. J Neurosci 25:247-251.

Franco SJ, Gil-Sanz C, Martinez-Garay I, Espinosa A, Harkins-Perry SR, Ramos C, Müller U (2012): Fate-restricted neural progenitors in the mammalian cerebral cortex. Science 337: 746-749.

Gal JS, Morozov YM, Ayoub AE, Chatterjee M, Rakic P, Haydar TF (2006): Molecular and morphological heterogeneity of neural precursors in the mouse neocortical proliferative zones. J Neurosci 26:1045-1056.

García-Moreno F, López-Mascaraque L, De Carlos JA (2007): Origins and migratory routes of murine Cajal-Retzius cells. J Comp Neurol 500:419-432.

- García-Moreno F, López-Mascaraque L, de Carlos JA (2008): Early telencephalic migration topographically converging into the olfactory cortex. Cereb Cortex 18:1239-1252. cortex. Nature 478:519-523.
García-Moreno F, Vasistha NA, Trevia N, Bourne JA, Molnár Z (2012): Compartmentalization of cerebral cortical germinal zones in a lissencephalic primate and gyrencephalic rodent. Cereb Cortex 22:482-492.

- Grant E, Hoerder-Suabedissen A, Molnár Z (2012): Development of the corticothalamic projections. Front Neurosci 6:53.

Haim A, Heth G, Pratt H, Nevo E (1983): Photoperiodic effects on thermoregulation in a 'blind' subterranean mammal. J Exp Biol 107: 59-64.

Hansen DV, Rubenstein JL, Kriegstein AR (2011): Deriving excitatory neurons of the neocortex from pluripotent stem cells. Neuron 70:645660.

Haubensak W, Attardo A, Denk W, Huttner WB (2004): Neurons arise in the basal neuroepithelium of the early mammalian telencephalon: a major site of neurogenesis. Proc Natl Acad Sci USA 101:3196-3201.

-Hawrylycz M, Lein E, Guillozet-Bongaarts AL, Guillozet-Bongaarts AL, Shen EH, Ng L, Miller JA, van de Lagemaat LN, Smith KA, Ebbert A, Riley ZL, Abajian C, Beckmann CF, Bernard A, Bertagnolli D, Boe AF, Cartagena PM, Chakravarty MM, Chapin M, Chong J, Dalley RA, Daly BD, Dang C, Datta S, Dee N, Dolbeare TA, Faber V, Feng D, Fowler DR, Goldy J, Gregor BW, Haradon Z, Haynor DR, Hohmann JG, Horvath S, Howard RE, Jeromin A, Jochim JM, Kinnunen M, Lau C, Lazarz ET, Lee C, Lemon TA, Li L, Li Y, Morris JA, Overly CC, Parker PD, Parry SE, Reding M, Royall JJ, Schulkin J, Sequeira PA, Slaughterbeck CR, Smith SC, Sodt AJ, Sunkin SM, Swanson BE, Vawter MP, Williams D, Wohnoutka P, Zielke HR, Geschwind DH, Hof PR, Smith SM, Koch C, Grant SG, Jones AR (2012): An anatomically comprehensive atlas of the adult human brain transcriptome. Nature 489:391-399.

Heil P, Bronchti G, Wollenberg Z, Scheich H (1991): Invasion of visual cortex by the auditory system in the naturally blind mole rat. Neuroreport 2:735-738.

-Henry EC, Remple MS, O'Riain MJ, Catania KC (2006): Organization of somatosensory corti$\mathrm{cal}$ areas in the naked mole-rat (Heterocephalus glaber). J Comp Neurol 495:434-452.

-Herculano-Houzel S, Collins C, Wong P, Kaas JH (2007): Cellular scaling rules for primate brains. Proc Natl Acad Sci USA 104:35623567.

Hevner RF (2006): From radial glia to pyramidalprojection neuron: transcription factor cascades in cerebral cortex development. Mol Neurobiol 33:33-50.

Hevner RF, Haydar TF (2012): The (not necessarily) convoluted role of basal radial glia in cortical neurogenesis. Cereb Cortex 22:465-468.

Hevner RF, Hodge RD, Daza RA, Englund C (2006): Transcription factors in glutamatergic neurogenesis: conserved programs in neocortex, cerebellum, and adult hippocampus. Neurosci Res 55:223-233. 
-Imayoshi I, Sakamoto M, Yamaguchi M, Mori K, Kageyama R (2010): Essential roles of Notch signaling in maintenance of neural stem cells in developing and adult brains. J Neurosci 30: 3489-3498.

-Itoh Y, Moriyama Y, Hasegawa T, Endo TA, Toyoda T, Gotoh Y (2013): Scratch regulates neuronal migration onset via an epithelialmesenchymal transition-like mechanism. Nat Neurosci 16:416-425.

-Johnson MB, Kawasawa YI, Mason CE, Krsnik Z, Coppola G, Bogdanović D, Geschwind DH, Mane SM, State MW, Sestan N (2009): Functional and evolutionary insights into human brain development through global transcriptome analysis. Neuron 62:494-509.

Kaas JH (2013): The evolution of brains from early mammals to humans. Wiley Interdiscip Rev Cogn Sci 4:33-45.

Kang HJ, Kawasawa YI, Cheng F, Zhu Y, Xu X, Li M, Sousa AM, Pletikos M, Meyer KA, Sedmak G, Guennel T, Shin Y, Johnson MB, Krsnik Z, Mayer S, Fertuzinhos S, Umlauf S, Lisgo SN, Vortmeyer A, Weinberger DR, Mane S, Hyde TM, Huttner A, Reimers M, Kleinman JE, Sestan N (2011): Spatio-temporal transcriptome of the human brain. Nature 478:483489.

-Kawaguchi A, Ikawa T, Kasukawa T, Ueda HR, Kurimoto K, Saitou M, Matsuzaki F (2008): Single-cell gene profiling defines differential progenitor subclasses in mammalian neurogenesis. Development 135:3113-3124.

-Kelava I, Reillo I, Murayama AY, Kalinka AT, Stenzel D, Tomancak P, Matsuzaki F, Lebrand C, Sasaki E, Schwamborn JC, Okano H, Huttner WB, Borrell V (2012): Abundant occurrence of basal radial glia in the subventricular zone of embryonic neocortex of a lissencephalic primate, the common marmoset Callithrix jacchus. Cereb Cortex 22:469-481.

Kott O, Šumbera R, Němec P (2010): Light perception in two strictly subterranean rodents: life in the dark or blue? PLoS One 5:e11810.

-Kowalczyk T, Pontious A, Englund C, Daza RA, Bedogni F, Hodge R, Attardo A, Bell C, Huttner WB, Hevner RF (2009): Intermediate neuronal progenitors (basal progenitors) produce pyramidal-projection neurons for all layers of cerebral cortex. Cereb Cortex 19: 2439-2450.

-Kriegstein A, Noctor S, Martínez-Cerdeño V (2006): Patterns of neural stem and progenitor cell division may underlie evolutionary cortical expansion. Nat Rev Neurosci 7:883890.

Lein ES, Hawrylycz MJ, Ao N, Ayres M, Bensinger A, Bernard A, Boe AF, Boguski MS, Brockway KS, Byrnes EJ, Chen L, Chen L, Chen TM, Chin MC, Chong J, Crook BE, Czaplinska A, Dang CN, Datta S, Dee NR, Desaki AL, Desta T, Diep E, Dolbeare TA, Donelan MJ, Dong HW, Dougherty JG, Duncan BJ, Ebbert AJ, Eichele G, Estin LK, Faber C, Facer BA, Fields R, Fischer SR, Fliss TP, Frensley C, Gates SN, Glattfelder KJ, Halverson KR, Hart MR, Hohmann JG, Howell MP,
Jeung DP, Johnson RA, Karr PT, Kawal R, Kidney JM, Knapik RH, Kuan CL, Lake JH, Laramee AR, Larsen KD, Lau C, Lemon TA, Liang AJ, Liu Y, Luong LT, Michaels J, Morgan JJ, Morgan RJ, Mortrud MT, Mosqueda NF, Ng LL, Ng R, Orta GJ, Overly CC, Pak TH, Parry SE, Pathak SD, Pearson OC, Puchalski RB, Riley ZL, Rockett HR, Rowland SA, Royall JJ, Ruiz MJ, Sarno NR, Schaffnit K, Shapovalova NV, Sivisay T, Slaughterbeck CR, Smith SC, Smith KA, Smith BI, Sodt AJ, Stewart NN, Stumpf KR, Sunkin SM, Sutram M, Tam A, Teemer CD, Thaller C, Thompson CL, Varnam LR, Visel A, Whitlock RM, Wohnoutka PE, Wolkey CK, Wong VY, Wood M, Yaylaoglu MB, Young RC, Youngstrom BL, Yuan XF, Zhang B, Zwingman TA, Jones AR (2007): Genome-wide atlas of gene expression in the adult mouse brain. Nature 445:168-176.

Lui JH, Hansen DV, Kriegstein AR (2011): Development and evolution of the human neocortex. Cell 146:18-36.

Marín-Padilla M (1971): Early prenatal ontogenesis of the cerebral cortex (neocortex) of the cat (Felis domestica). A Golgi study. I. The primordial neocortical organization. Z Anat Entwicklungsgesch 134:117-145.

Martinez-Cerdeño V, Noctor SC, Kriegstein AR (2006): The role of intermediate progenitor cells in the evolutionary expansion of the cerebral cortex. Cereb Cortex 16:1152-i161.

McConnell SK, Ghosh A, Shatz CJ (1989): Subplate neurons pioneer the first axon pathway from the cerebral cortex. Science 245:978982.

Métin C, Alvarez C, Moudoux D, Vitalis T, Pieau C, Molnár Z (2007): Conserved pattern of tangential neuronal migration during forebrain development. Development 134:28152827.

Miquelajáuregui A, Valera-Echavarría A, Ceci ML, García-Moreno F, Ricaño I, Hoang K, Frade-Pérez D, Portera-Cailliau C, Tamariz E, De Carlos JA, Westphal H, Zhao Y (2010): LIM-homeobox gene Lhx5 is required for normal development of Cajal-Retzius cells. J Neurosci 30:10551-10562.

- Miyata T, Kawaguchi A, Saito K, Kawano M, Muto T, Ogawa M (2004): Asymmetric production of surface-dividing and non-surfacedividing cortical progenitor cells. Development 131:3133-3145.

Molnár Z (2011): Evolution of cerebral cortical development. Brain Behav Evol 78:94-107.

Molnár Z, Belgard TG (2012): Transcriptional profiling of layers of the primate cerebral cortex. Neuron 73:1053-1055.

Molnár Z, Butt SJB (2013): Best-laid schemes for interneuron origin of mice and men. Nat Neurosci 16:1512--1514.

Molnár Z, Clowry G (2012): Cerebral cortical development in rodents and primates. Prog Brain Res 195:45-70.

Molnár Z, Garel S, López-Bendito G, Maness P, Price DJ (2012): Mechanisms controlling the guidance of thalamocortical axons through the embryonic forebrain. Eur J Neurosci 35: 1573-1585.

Murphy WJ, Pevzner PA, O’Brien JO (2004): Mammalian phylogenomics comes of age. Trends Genet 20:631-639.

Necker R, Rehkämper G, Nevo E (1992): Electrophysiological mapping of body representation in the cortex of the blind mole rat. Neuroreport 3:505-508.

Nelson BR, Hodge RD, Bedogni F, Hevner RF (2013): Dynamic interactions between intermediate neurogenic progenitors and radial glia in embryonic mouse neocortex: potential role in Dll1-Notch signaling. J Neurosci 33: 9122-9139.

Němec P, Altmann J, Marhold S, Burda H, Oelschläger HHA (2001): Neuroanatomy of magnetoreception: the superior colliculus involved in magnetic orientation in a mammal. Science 294:366-368.

Němec P, Burda H, Peichl L (2004): Subcortical visual system of the African mole-rat Cryptomys anselli: to see or not to see? Eur J Neurosci 20:757-768.

-Němec $\mathrm{P}$, Cvekova $\mathrm{P}$, Benada $\mathrm{O}$, Wielkopolska E, Olkowicz S, Turlejski K, Burda H, Bennett NC, Peichl L (2008): The visual system in subterranean African mole-rats (Rodentia, Bathyergidae): retina, subcortical visual nuclei and primary visual cortex. Brain Res Bull 75:356-364.

-Němec P, Cvekova P, Burda H, Benada O, Peichl L (2007): Visual systems and the role of vision in subterranean rodents: diversity of retinal properties and visual system designs; in Begall S, Burda H, Schleich CE (eds): Subterranean Rodents: News from Underground. Heidelberg, Springer, pp 129-160.

Nevo E (1999): Mosaic Evolution of Subterranean Mammals: Regression, Progression and Global Convergence. Oxford, Oxford University Press.

Noctor SC, Flint AC, Weissman TA, Dammerman RS, Kriegstein AR (2001): Neurons derived from radial glial cells establish radial units in neocortex. Nature 409:714-720.

Noctor SC, Martínez-Cerdeño V, Ivic L, Kriegstein AR (2004): Cortical neurons arise in symmetric and asymmetric division zones and migrate through specific phases. Nat Neurosci 7:136-44

Nonaka-Kinoshita M, Reillo I, Artegiani B, Martínez-Martínez MA, Nelson M, Borrell V, Calegari F (2013): Regulation of cerebral cortex size and folding by expansion of basal progenitors. EMBO J 32:1817-1828.

-Oelschläger HHA, Nakamura M, Herzog M, Burda H (2000): Visual system labeled by c-Fos immunohistochemistry after light exposure in the 'blind' subterranean Zambian mole-rat (Cryptomys anselli). Brain Behav Evol 55:209-220.

O'Leary DDM, Chou SJ, Sahara S (2007): Area patterning of the mammalian cortex. Neuron 56:252-269.

Pedraza M, De Carlos JA (2012): A further analysis of olfactory cortex development. Front Neuroanat 6:35. 
-Pedraza M, Hoerder-Suabedissen A, Molnar Z, De Carlos JA (2014): A new extracortical origin of some murine subplate cell population. PNAS (in review).

Peichl L, Němec P, Burda H (2004): Unusual cone and rod properties in subterranean African mole-rats (Rodentia, Bathyergidae). Eur J Neurosci 19:1545-1558.

-Pimeisl I-M, Tanriver Y, Daza RA, Vauti F, Hevner RF, Arnold H-H, Arnold SJ (2013): Generation and characterization of a tamoxifen-inducible Eomes ${ }^{\mathrm{CreER}}$ mouse line. Genesis 51:725-733.

Pontious A, Kowalczyk T, Englund C, Hevner RF (2008): Role of intermediate progenitor cells in cerebral cortex development. Dev Neurosci 30:24-32.

Rakic P (1972): Mode of cell migration to the superficial layers of the fetal monkey neocortex. J Comp Neurol 145:61-84.

Rakic P (1988): Specification of cerebral cortical areas. Science 241:170-176.

-Rash BG, Tomasi S, Lim HD, Suh CY, Vaccarino FM (2013): Cortical gyrification induced by fibroblast growth factor 2 in the mouse brain. J Neurosci 33:10802-10814.

Reillo I, de Juan Romero C, García-Cabezas MÁ, Borrell V (2011): A role for intermediate radial glia in the tangential expansion of the mammalian cerebral cortex. Cereb Cortex 21: 1674-1694.

-Sasaki S, Tabata H, Tachikawa K, Nakajima K (2008): The cortical subventricular zone-specific molecule Svet1 is part of the nuclear RNA coded by the putative netrin receptor gene Unc5d and is expressed in multipolar migrating cells. Mol Cell Neurosci 38:474483.
Shimogori T, Grove EA (2005): Fibroblast growth factor 8 regulates neocortical guidance of area-specific thalamic innervation. J Neurosci 25:6550-6560.

Smart IH, Dehay C, Giroud P, Berland M, Kennedy $H$ (2002): Unique morphological features of the proliferative zones and postmitotic compartments of the neural epithelium giving rise to striate and extrastriate cortex in the monkey. Cereb Cortex 12:37-53.

Stahl R, Walcher T, De Juan Romero C, Pilz GA, Cappello S, Irmler M, Sanz-Aquela JM, Beckers J, Blum R, Borrell V, Götz M (2013): Trnp1 regulates expansion and folding of the mammalian cerebral cortex by control of radial glial fate. Cell 153:535-49.

Tabata H, Nakajima K (2003): Multipolar migration: the third mode of radial neuronal migration in the developing cerebral cortex. J Neurosci 23:9996-10001.

Tamamaki N, Fujimori KE, Takauji R (1997): Origin and routes of tangentially migrating neurons in the developing neocortical intermediate zone. J Neurosci 17:8313-8323.

Tamamaki N, Nakamura K, Okamoto K, Kaneko $\mathrm{T}$ (2001): Radial glia is a progenitor of neocortical neurons in the developing cerebral cortex. Neurosci Res 41:51-60.

Tarabykin V, Stoykova A, Usman N, Gruss P (2001): Cortical upper layer neurons derive from the subventricular zone as indicated by Svet1 gene expression. Development 128: 1983-1893.

Tuorto F, Alifragis P, Failla V, Parnavelas JG, Gulisano M (2003): Tangential migration of cells from the basal to the dorsal telencephalic regions in the chick. Eur J Neurosci 18:33883393.
Tyler WA, Haydar TF (2013): Multiplex genetic fate mapping reveals a novel route of neocortical neurogenesis, which is altered in the Ts65Dn mouse model of Down syndrome. J Neurosci 33:5106-5119.

Vasistha NA, Vasistha NA, Garcia-Moreno F, Arora S, Cheung AFP, Arnold SJ, Robertson EJ, Molnár Z (2014): Cortical and clonal contribution of Tbr2 expressing progenitors in the developing mouse brain. Cereb Cortex (in review).

Walsh C, Cepko CL (1993): Clonal dispersion in proliferative layers of developing cerebral cortex. Nature 362:632-635.

Wong P, Collins CE, Kaas JH (2010): Overview of sensory systems of Tarsius. Int J Primatol 31: 1002-1031.

Yoon KJ, Koo BK, Im SK, Jeong HW, Ghim J, Kwon MC, Moon JS, Miyata T, Kong YY (2008): Mind bomb 1-expressing intermediate progenitors generate notch signaling to maintain radial glial cells. Neuron 58:519531.

Zeng H, Shen EH, Hohmann JG, Oh SW, Bernard A, Royall JJ, Glattfelder KJ, Sunkin SM, Morris JA, Guillozet-Bongaarts AL, Smith KA, Ebbert AJ, Swanson B, Kuan L, Page DT, Overly CC, Lein ES, Hawrylycz MJ, Hof PR, Hyde TM, Kleinman JE, Jones AR (2012): Large-scale cellular-resolution gene profiling in human neocortex reveals species-specific molecular signatures. Cell 149:483-496.

Zimmer C, Tiveron MC, Bodmer R, Cremer H (2004): Dynamics of Cux2 expression suggests that an early pool of SVZ precursors is fated to become upper cortical layer neurons. Cereb Cortex 14:1408-1420. 